\title{
Prioritizing Technology Adoption Dynamics among SMEs
}

\author{
Mohammad Naushad, Sulphey M. M. \\ College of Business Administration, Prince Sattam Bin Abdulaziz University, P O Box-165, Alkharj- 11942, \\ Kingdom of Saudi Arabia (KSA)
}

\begin{abstract}
Though Small and Medium Enterprises (SMEs) are engines of growth, due to multiple reasons they are low in adoption of digitalization and technology. This paper seeks to provide a framework to prioritize the factors/dynamics towards adoption of information and communication technologies (ICT). Through review of literature and applying Analytical Hierarchy Process (AHP), relevant factors have been chalked out and arranged in terms of priority. The findings indicate SMEs adopt ICT to have a relative advantage over competitors. Affordability, ease of use, value creation and productivity are top priority reasons. Profitability and top management support are other prime factors that stimulate ICT adoption. Other relevant factors include technological self-efficacy and personal characteristics of entrepreneurs.
\end{abstract}

Keywords - SMEs, ICT adoption, Analytical Hierarchy Process, AHP

\section{Introduction}

Small and Medium Enterprises (SMEs) now play a dominant role in almost all economies, irrespective of it being developed or developing. They have been contributing substantially towards national income, employment generation, sustainable economic growth, etc.

DOI: 10.18421/TEM93-21

https://doi.org/10.18421/TEM93-21

Corresponding author: Mohammad Naushad, College of Business Administration, Prince Sattam Bin Abdulaziz University, Saudi Arabia.

Email: meetnaushad@gmail.com

Received: 16 April 2020.

Revised: 29 July 2020.

Accepted: 04 August 2020.

Published: 28 August 2020.

(cc) BY-NC-ND(C) 2020 Dr. Mohammad Naushad \& Sulphey M. M; published by UIKTEN. This work is licensed under the Creative Commons Attribution-NonCommercialNoDerivs 4.0 License.

The article is published with Open Access at www.temjournal.com
In any country, SMEs contribute significantly towards GDP and account for over $90 \%$ of the business population [1]. However, SMEs are now facing multiple socio-economic, business and technological challenges. One of the serious challenges faced by SMEs is from digitization and technology adoption.

Technology and digitalization are now radically changing human lives. This is also reflected in the business world, which is marked by dramatic and disruptive tendencies. Digitalization is here to stay, and for any business to achieve the required sustainable growth. There is a definite need to adapt Information and Communication Technology (ICT) wholeheartedly. In the current volatile and uncertain world, where ICT decides the tempo of competition and success; SMEs face multiple unforeseen challenges. Further, in this digital age, it is no exaggeration to say that it is impossible for businesses to survive unless they adopt ICT.

The current competitive, volatile and challenging business scenario has compelled SMEs to enhance quality of operations through innovation. These are essential to sustain and thrive. Experiences show that SMEs that embrace ICT grow multiple times faster than their sluggard competitor. Literature is replete with evidences which show that ICT and digital technologies have been successful in significant positive improved in the performance, productivity and competitiveness of SMEs [2], [3]. This highlights the significant role played by digitalization in the growth of SMEs.

Since the Kingdom of Saudi Arabia (KSA) is in a crucial transition phase, the importance of SMEs in the economy cannot be underestimated. Among other challenges faced by the economy, KSA has the definite and unequivocal need to generate employment while moving away from the traditional oil-based economy [4]. SMEs can be considered as one of the major panaceas for all these requirements. The present study indents to identify the level of ICT adaptation by SMEs in KSA, and the objective is set against this backdrop. 


\section{Review of Literature}

This section is divided into two parts. The first part discusses the importance of SMEs and the second deals with the dynamics of ICT adoption. Volumes of literature have accumulated SMEs and ICT adoption. As such the researchers have resorted to "scoping review" of the two topics. Since the present study was done in KSA, which is categorized as developing, the review of literature is mostly focused on studies from developing economies. However, wherever required studies from developed world has also been considered. The earlier literature on technology adoption and usage suggest that the level of technology adoption among the SMEs in developing countries have been mostly limited to low to medium levels. In many instances, these technologies are merely limited to internet, websites, e-mails and customized application software only. However, manufacturing firms have to rely more on hardware-based technology. Since the focus of the present study is on the manufacturing SMEs; which adopt internet, e-mails, electronic pay systems, electronic billing, networking, B2B e-commerce, etc.; some of the technology adopted by SMEs are categorized under information technologies and some as communication technologies. Henceforth, the present study uses the technology as information and communication technology.

\subsection{Criterion of SMEs for ICT adoption: Why should SMEs adopt the ICT?}

A host of descriptive variables that has the capability to influence adoption of digital technology has been found in literature [5], [6]. A few such variables include computerization, e-commerce, inter-organizational systems, economic variables, environmental variables and personal variables of individuals [7]. The Diffusion of Innovation Theory (DOI), [8] provides theoretical underpinnings about ICT adoption and usage [7]. Further, in DOI, [9] proposed five attributes of innovations adoption, namely "perceived relative advantage, compatibility, complexity, trialability, and observability". However, subsequent researches in the same field have added further to the dimensions propounded by [9]. The highly significant and utilized attributes of DOI are perceived relative advantage, compatibility and complexity [7], [10].

The current study has adopted two attributes suggested by [8], [9] that perceived relative advantage and compatibility. While perceived relative advantage, which can be defined as "the degree to which an innovation is perceived as being better than the idea it supersedes"; compatibility is considered as "the degree to which an innovation is perceived as consistent with the existing values, past experiences, and needs of potential adopters" [9]. Other variables adopted in the current study include affordability, ease of use, value creation and productivity. Affordability indicates the cost aspects of adopting the technology. Due to scarcity of resources, affordability of ICT among SMEs within developing and developed nations remains a matter of concern among the researchers and policy makers. The affordability of technology is considered as a major factor for creating digital divide among SMEs and large organisations. Similar to affordability, another factor which is considered important for SMEs to adopt ICT is ease of use. SMEs are found to adopt technology which is easy to use [5]. Perceived ease of use is one of the important contributions of IT. Perceived ease of use was found to positively affect the decision of adopting the ICT among SMEs [11]. Perceived usefulness of technologies was also connected with the intent to use among SMEs [11]. Technologies that create a fairly high amount of value would have high level of adoptability among SMEs.

The factors which influence the decision of SMEs owners for adoption of ICT could be broadly categorized under individual dynamics, organisational dynamics, technological dynamics, economic and Environmental dynamics. They are now discussed in detail.

\subsubsection{Value creation and productivity}

Technologies that create value and perceived as contributing towards the efficiency and productivity in SMEs were highly acceptable among SMEs. ICT has been found to be capable of adding value among SMEs [12]. Value addition can take any form. It could be the level of customer satisfaction, better services and products, improvement in the efficiency and effectiveness of employees, minimization of waste and emissions from operations, and costs and risk reductions [12], [13].

\subsubsection{Individual Dynamics}

SMEs are mostly sole proprietorship or partnership business, controlled by one person or a group of limited people. As such, individual characteristics have great influence over the ICT adoption decisions. Personality variables of entrepreneurs have been found to be closely linked to positive adoption of innovative technologies [14]. The individual personal characteristics could be summed as greater empathy, less dogmatic, greater ability to deal with abstractions, rationality and more favorable attitude toward change [7]. 


\subsubsection{Environmental Dynamics}

Environmental dynamics are the factors that describe the environment. They exert an enormous role in strategy formulation in large organizations as well as SMEs. The external environment has been identified as a key "explanatory variable" that influence SMEs towards ICT adoption [13], [15]. A few environmental factors that need to be provided the due importance include the various stakeholders like suppliers, customers, government agencies and competitors [16], [17]. Technological challenges faced by SMEs have been a subject matter of empirical discussion. Findings suggest that technological challenges faced by SMEs from the environment include, among other aspects, the lack of institutional support [18]. External business environment also has a bearing on ICT adoption among SMEs [19]. A few external environments that play significant roles include competitors, technology-vendor relationship and inter-firm dependency [20], [25]. The role of government in the integration of technology for SMEs has been emphasized by many social researchers [16].

\subsubsection{Organizational Dynamics}

Organizational factors are the inside forces that are controllable by the organizations. These factors are inevitable forces that prompt organizations to adopt the technology. Organizational characteristics such as support from the top management, organizational readiness, communication and communications medium-channels \& quality, information and management support systems, networking \& networking structures, organizational structures and quality orientation prompt organizations to adopt the information systems (IS) and technologies [10], [17]. Governmental role towards ICT adoption is mostly associated with financial supports like tax holidays on infrastructure, development of sites and applications, etc. [21]. [22] observed that ICT could improve both external and internal organizational communications.

\subsubsection{Economic Dynamics}

Positive effects of ICT in SMEs and economic benefits to economy have been the subject of empirical examination by a number of social scholars [23]. A few positive effects include possibility of new investment avenues, enhanced productivity and profitability, better market share and value, etc. Certain other benefits include savings, process flexibility and efficiency, quality service and the resultant satisfaction to customers, etc. [24] found that adoption of ICT improves the overall performance of SMEs, including economic. ICT adoption could also facilitate multiple fresh investment avenues. [23] explained that economic benefits of ICT for firms could contribute towards economic growth, labor productivity, profitability and consumer welfare. The performances of SMEs were found to improve multi-fold if organizational processes were aligned with ICT investments. Major factors identified as essential for ICT adoption include perceived benefits, costs, ICT knowledge, external pressures and government support [21]. For a better understating, the factors discussed above are presented as Table 1.

\section{Table 1. Literature Mapping of ICT Dynamics among} SMEs

\begin{tabular}{|c|l|l|}
\hline No. & Dynamics & \multicolumn{1}{|c|}{ Studies } \\
\hline 1 & $\begin{array}{l}\text { Individual } \\
\text { Dynamics }\end{array}$ & {$[5],[6],[10],[15]$.} \\
\hline 2 & $\begin{array}{l}\text { Organisational } \\
\text { Dynamics }\end{array}$ & $\begin{array}{l}{[13],[5],[21],[10],[15],[17],} \\
{[26] .}\end{array}$ \\
\hline 3 & $\begin{array}{l}\text { Technological } \\
\text { Dynamics }\end{array}$ & $\begin{array}{l}{[13],[5],[6],[10],[18],[21],} \\
{[26] .}\end{array}$ \\
\hline 4 & $\begin{array}{l}\text { Economic } \\
\text { Dynamics }\end{array}$ & {$[15],[16],[23]$.} \\
\hline 5 & $\begin{array}{l}\text { Environmental } \\
\text { Dynamics }\end{array}$ & $\begin{array}{l}{[13],[5],[6],[10],[15],[17],} \\
{[21],[26] .}\end{array}$ \\
\hline
\end{tabular}

Based on the discussion, the following model is constructed.

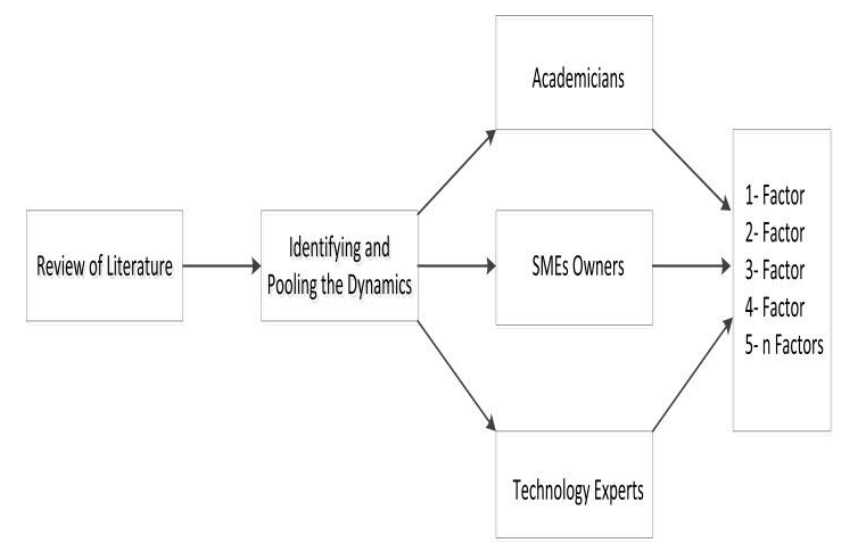

Stage-1: Identification of $\longrightarrow$ Stage-2: Pooling of $\longrightarrow$ Stage-3: Analysis Stage $\longrightarrow$ Stage-4: Prioritization
Factors from literature

Figure 1. Research Model for Study

\section{Methodology}

The present study has adopted a case-based approach in order to chalk out the factors that facilitate ICT adoption and to arrange them on the priority or importance to SMEs. This approach is considered useful in situations in which a greater interaction with the protagonist is required. The study 
has attempted to identify and prioritize the factors that prompt SMEs to adopt ICT.

Normally a decision to adopt ICT is done after taking into consideration a series of factors. Specifically, SMEs tend to suffer from scarcity of resources like human capital, physical and financial resources. A brainstorming with different stakeholders is required to understand the forces and factors that influence decision regarding ICT adoption. Normally a deficiency of fuzziness is created during the decision-making session. In such situations, unique, innovative techniques and methodologies are required to arrive at appropriate decisions. On such techniques used to arrive at appropriate decision Analytical Hierarchy Process (AHP) is based.

If there are considerable inputs, criteria and alternatives to overcome, AHP would be ideally suited. AHP is a multi-criterion decision making tool developed by [27]. It is a powerful tool that facilitates solving complex decision-making problems. AHP can be used for complex economic, socio-political and technological problems [28]. While using AHP, the problems are decomposed into several sub-problems or criteria into a hierarchical level. This is further decomposed in sub criterion or alternatives. Thus AHP is considered as a multi criterion decision making tool with additive weighting process and pair to pair comparison [28]. A typical AHP process comprises a five-stage process. The stage 1 of the process includes the construction of hierarchy structure. This stage decomposes the attribute and sub-attribute tills the lowest level of hierarchy [28]. In stage two the judgement matrix is constructed. Weights are assigned to each criteria and sub-criterion in the third stage. In the subsequent stage, sequencing and hierarchy of criterion are done. The final stage is devoted to the ranking of alternatives.

\subsection{Case Study Approach}

As stated earlier, this study is aimed at expounding a framework to prioritise the technology adoption dynamics for SMEs. To achieve the objectives, an earnest view is needed from the stakeholders who contribute to the entire process. A case study approach is an appropriate method for such studies. There are instances in literature which shows the case study based approached have been traced by Analytic Hierarchy Process (AHP) methodology [29]. The AHP, which is a multicriteria decision-making tool developed by [27] has been deployed to sort out and prioritise the final choices emerged on the basis of respondents' responses. AHP utilises multi criterion decision making approach by classifying the steps into objectives, criteria and alternatives. The study also exercises consistency analysis, which examines the reliability of the given responses, and motivates further responses if the responses are inconsistent. Moreover, AHP also does a pairwise comparison before the final results. These features of AHP qualifie it as one of the most appropriate tools for case-based studies [29].

The organization chosen for the current study is a manufacturing \& material production company. The size, capital structure and number of employees categorized it as SME. Notably SMEs in KSA are considered as those companies/businesses which are independent commercial entities that employ less than 249 employees and has a revenue less than SAR 200 million (www.smea.gov.sa). The essential ICT tools used by the company were internet, email, video conferencing, LAN, intercom, intranet, website automation devices, etc.

\subsection{AHP Application}

The objective of current research is to prioritize the dynamics of ICT adoption for SMEs. By stating the objective we can determine the level one of the hierarchy. The second stage of AHP consists of defining the criterion. The criterion for the current study emerged from the discussion made in the review of literature. Based on it, the criterion was divided among four categories: namely, affordability $\&$ ease of use, value creation \& productivity, and relative advantage \& compatibility. The third stage of AHP consists of alternatives which can be pronounced as the specific reason of ICT adoption. In short, it can be summed that stage one is for stating the objectives, stage two is for criterion and stage three is for the alternatives. This can be seen from Figure 2, which is depicted below:

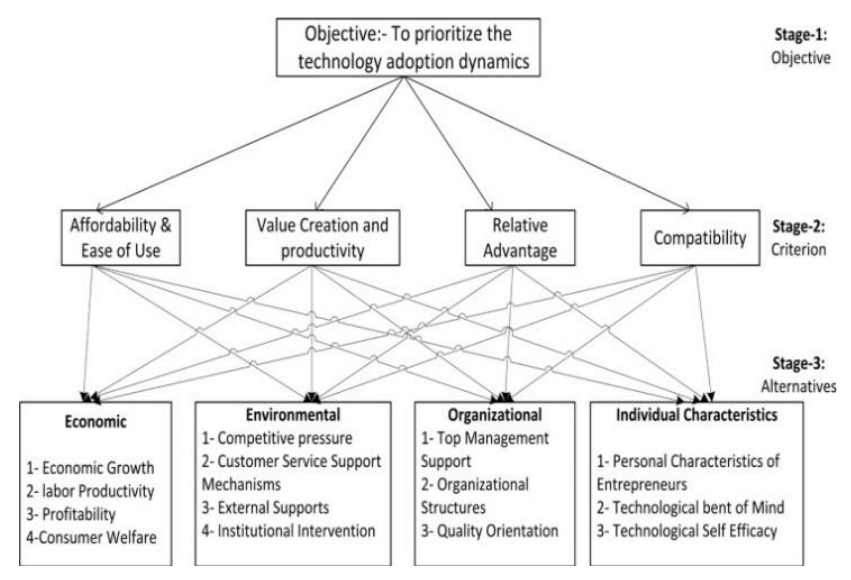

Figure 2. AHP Model for ICT Adoption among SMEs

After constructing the above mentioned three levels, the next step is to analyze the data. The data was collected from three stakeholders mentioned in Figure 1, namely academicians, SME owner and 
technology experts/practitioners. The data so collected was analysed by using Expert Choice ${ }^{\circledR}$ software. The rest of the stages mentioned in the above sections were executed by the software itself.

\section{Results}

Figure 2 presents 14 factors that motivate SMEs to adopt ICT practices. Notably these 14 factors are part of four different classifications known as alternatives in AHP model. To ascertain the priority of these factors using AHP, respondents were asked to do the pairwise comparison among the factors at each level of model. The comparison was made on a special AHP scale recommended by [28], i.e. (from 1-9, where 9 is extremely important and 1 is equally important).

The Expert Choice ${ }^{\circledR}$ software assigns the weights, based on priority to the antecedents at each level of hierarchy. Figure 3 presents that among the four criterion of ICT adoption "Relative Advantage" emerged as the highly preferred criteria for SMEs for ICT adoption followed by "Affordability and ease of use", "Value creation and productivity" and "Compatibility" with priority weights of 38.1, 28.6, 24.3, and 9 percent respectively.
Figure 4 shows the priorities of alternatives, which indicates that "Technological self-efficacy", "Personal characteristics of entrepreneurs", "Top management support" "profitability" and "Competitive Pressures" have emerged as the top five dynamics of ICT adoption among SMEs with priority weights of 28.00, 18.50, 16.50, 6.40 and 5.70 per cent respectively.

In order to check whether the change in weights of criteria would cause any inconsistency in the results, sensitivity analysis was carried out. After a series of sensitivity analyses, it is found that technological self-efficacy; personal characteristics of entrepreneurs and top management support were undoubtedly the most important factors that motivated SMEs towards ICT adoption.

To perform the sensitivity analysis equal weight to the criterion were assigned. There were four criteria, where approximately 25 per cent weight was assigned to each criterion. Figure 5 (a) \& (b) presents the results of pre-sensitivity analysis, while figure 6 (a) and (b) provides the results of post sensitivity analysis. Figure 6 shows that changing the weights of criteria alter the priorities of alternatives. However, the top five alternatives were found to essentially remain the same. This indicates that the results are directed at the same direction and indicate a pattern. This shows that the alternatives that emerged from the analysis are robust enough to moderate changes in the criteria. Therefore, the priorities that emerged from the analyses could be sufficient and relied upon.

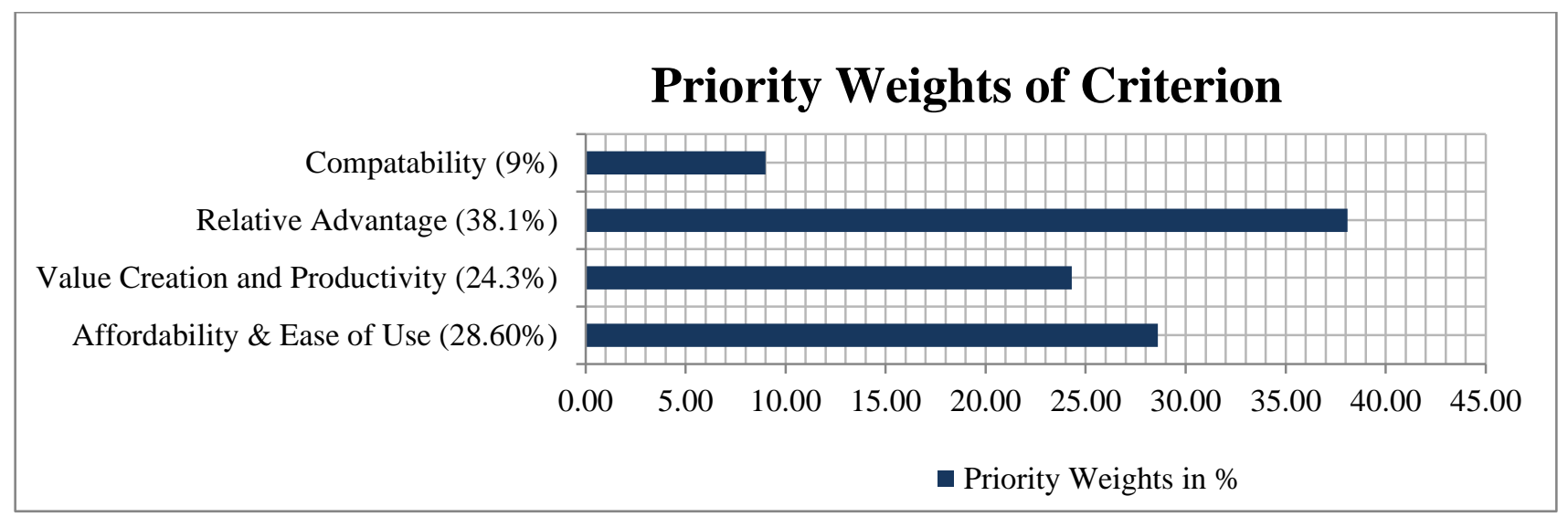

Figure 3. AHP Model for ICT Adoption among SMEs 


\section{Priority Weights in \%}

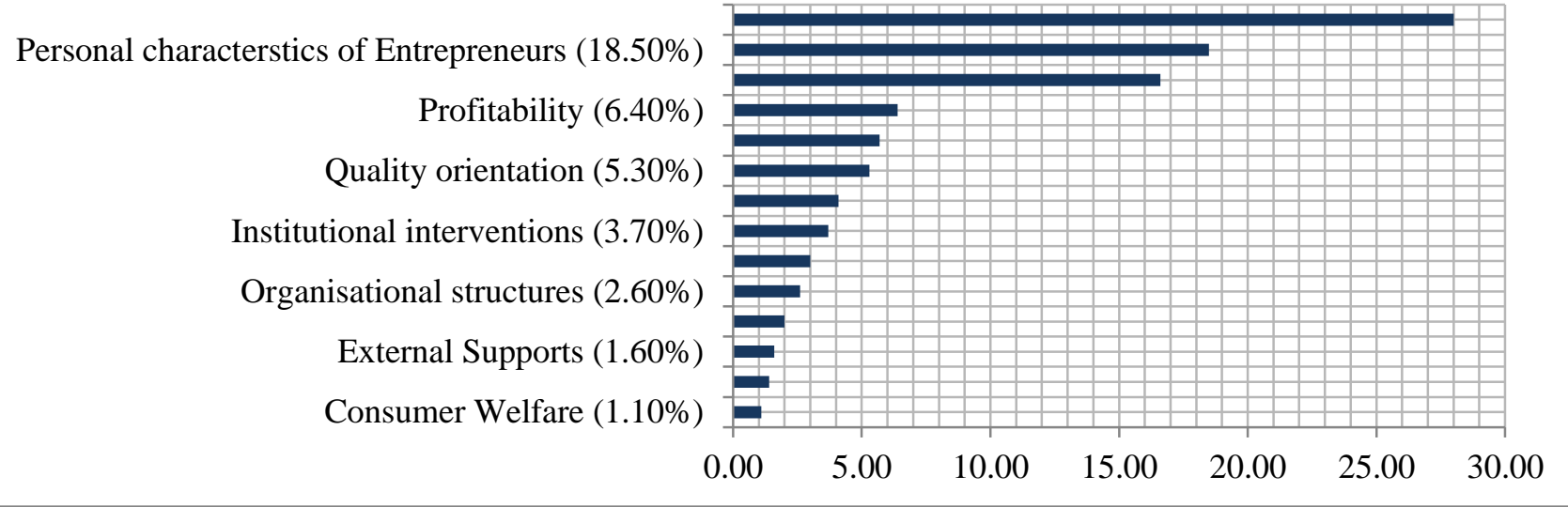

Figure 4. AHP Model for ICT Adoption among SMEs

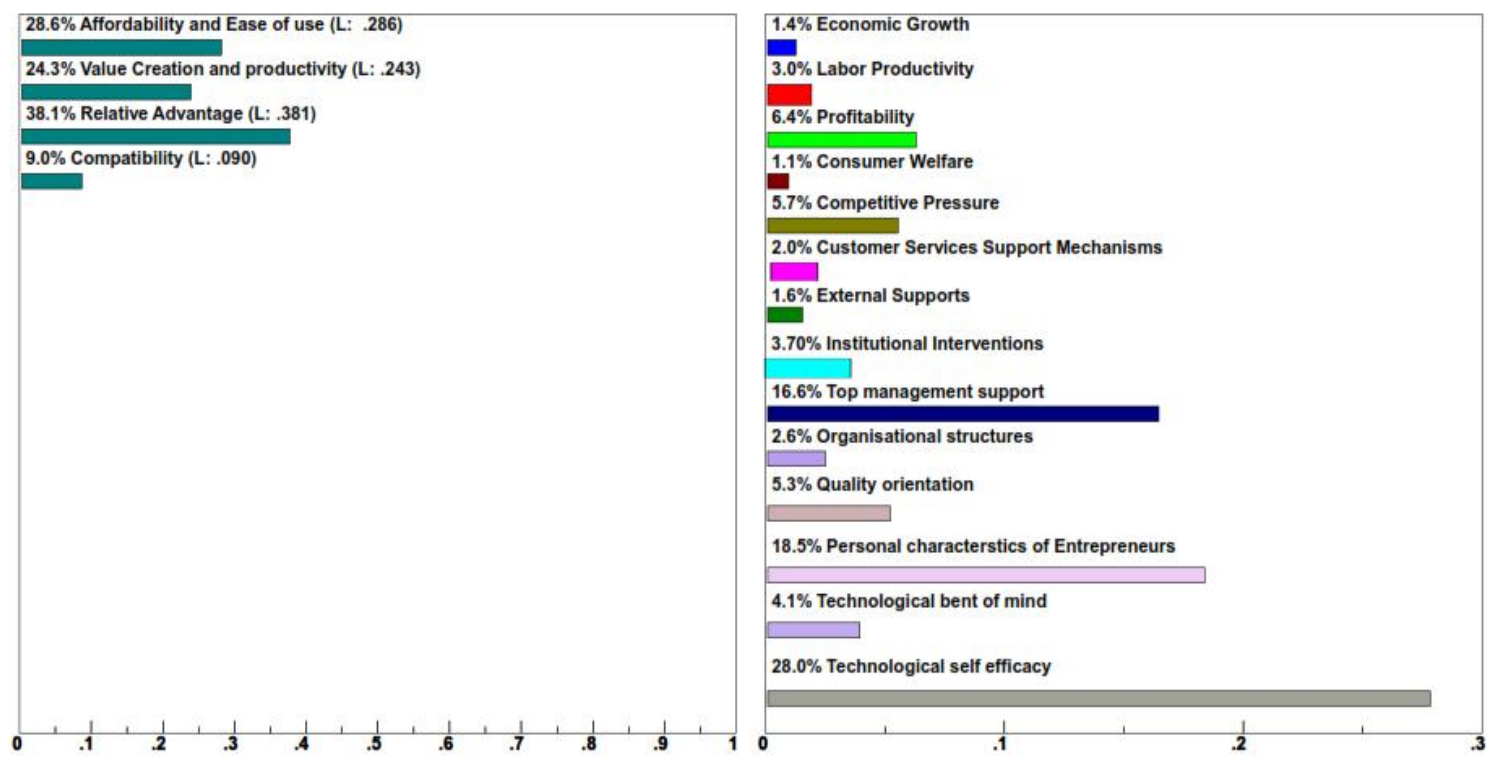

Figure 5 (a). Performance Sensitivity Analysis (Preliminary)

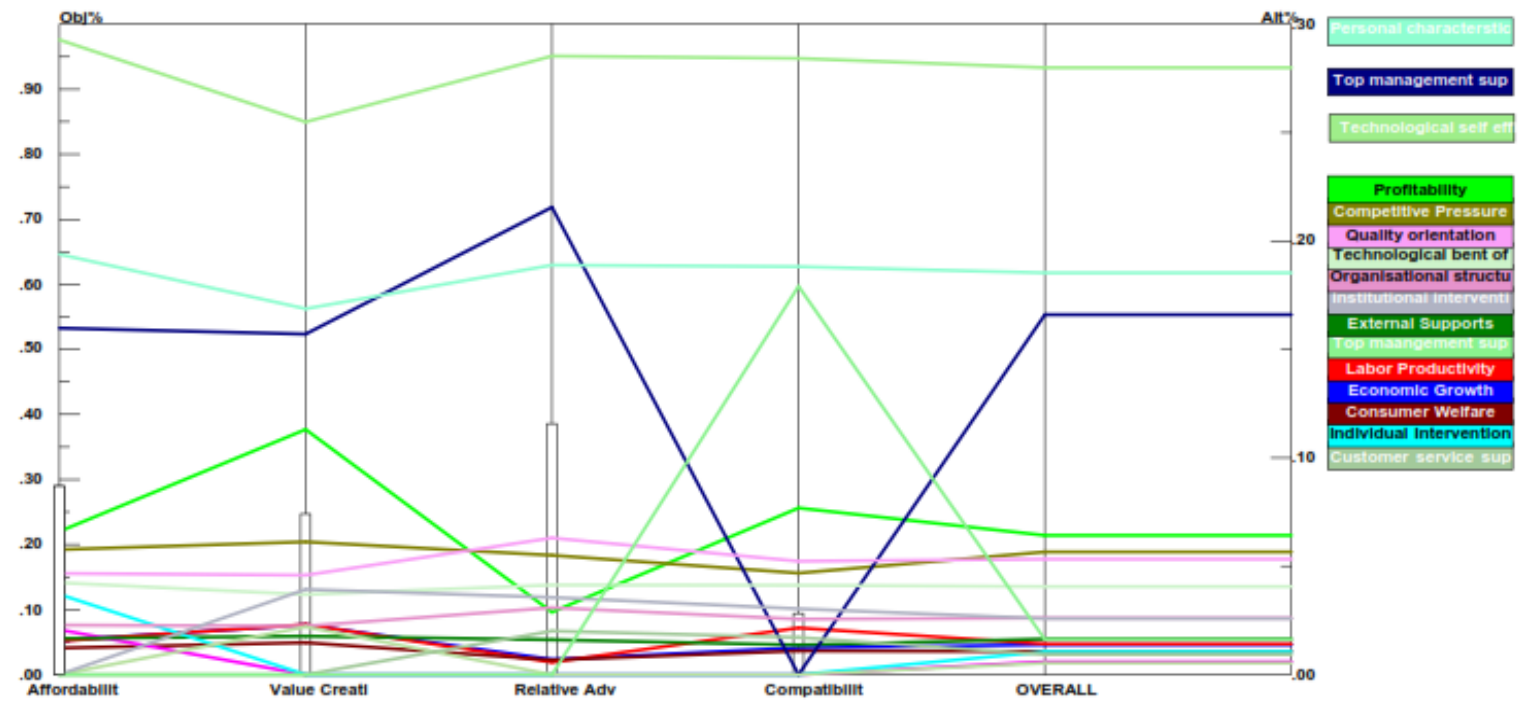

Figure 5 (b). Performance Sensitivity Analysis (Preliminary) 

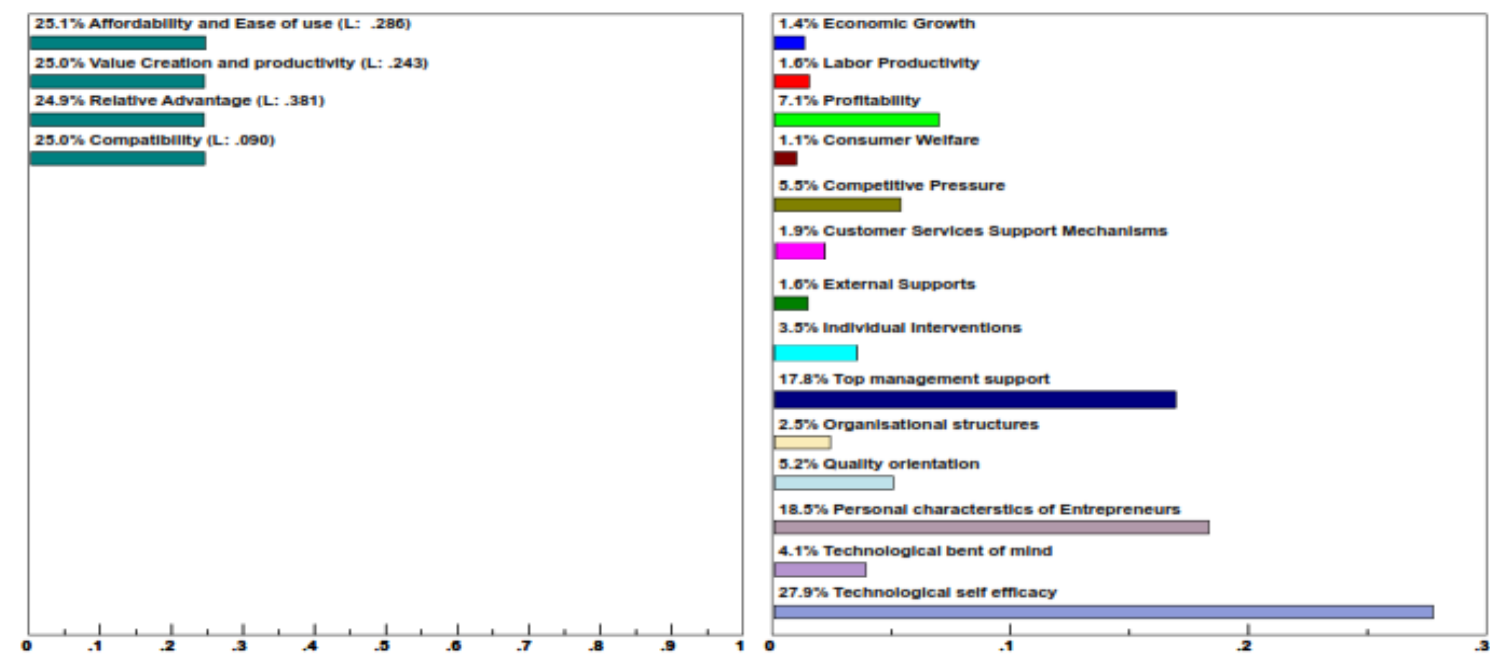

Figure 6 (a). Dynamic Sensitivity Analysis (Preliminary)

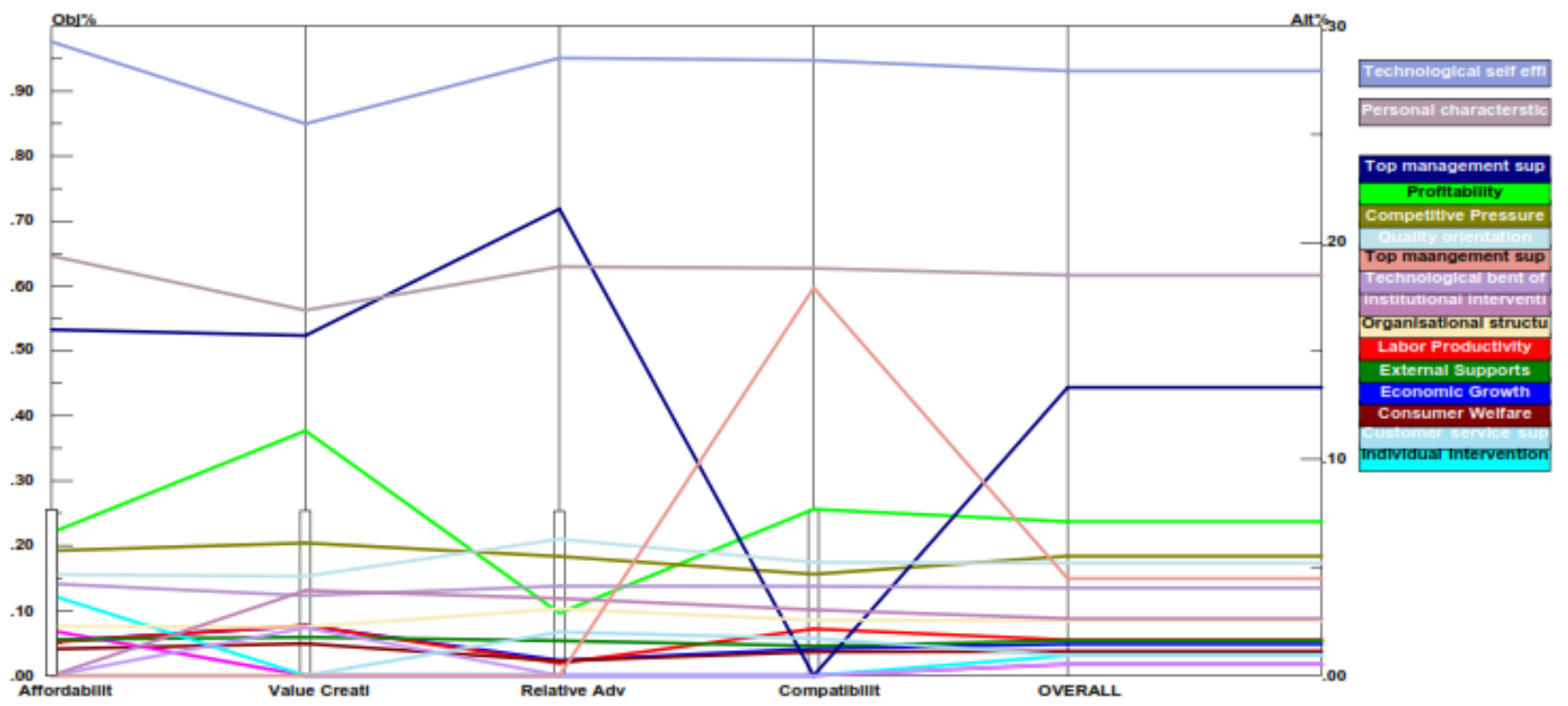

Figure $6($ b). Dynamic Sensitivity Analysis (Preliminary)

\section{Discussion}

The present study is aimed at devising a framework to prioritize the ICT adoption factors for SMEs. This was sought to be done by adopting a multi-criteria decision-making approach, i.e. AHP. A pool of factors was generated by doing a pervasive literature review. During the prioritization process, a case-based approach was utilized to enlist the adopted factors. The results from the analysis exhibited were found to be of exploratory in nature. The analysis found that technological self-efficacy is the leading factors of ICT adoption. Self-efficacy is a concept pioneered by Albert Bandura in 1995, which was defined as "the belief in self capabilities to perform or carried out the certain course of action in a given situation". However, Technological selfefficacy is the individual belief to learn and apply the information and communication resource such as computers, internet and other related things in a given environment. It is usually pronounced as the computer self-efficacy: however technological selfefficacy is more than computer self-efficacy. [10] in their meta-analysis study, found technological selfefficacy as one of the most important individual predictor of ICT adoption. The second most important dynamics for ICT adoption was "the personal characteristics of entrepreneurs". This can be identified as one of the components of individual characteristics adopted in the AHP model, and it is intuitive in nature. Since the case study was based on SMEs, and they are usually the small businesses started and operated by sole entrepreneurs, individual entrepreneur has substantial influence over the decision-making process of businesses. The personal characteristics of entrepreneurs such as positive perception, attitude towards technology will influence the decision of technology adoption [22]. 
Studies [10], [15] have established that an entrepreneur with technological bent of mind, is tech oriented personality, with good perception towards technology and with a positive attitude is more likely to adopt ICT. Moreover, the personal characteristics like age, gender, ethnicity, level of education are also some of the influencer that moderate the technology adoption decision of individuals [7].

Another key important dynamic of ICT adoption among SMEs is the "Top management support". It is implied that the top management with a better IT perspective is always in a better position to influence decisions like ICT adoption. Similarly, being on the top position, top manager also has the right to resources allocation for ICT facilities. [10] found top management support among the best predictors of ICT adoption among businesses. The next significant dynamics is "profitability". Profitability is presumed to be the sole reason of existence of any business. So it obvious that SMEs focuses on ICT adoption to improve their profitability. Profitability could also be seen as the benefits of technology.

Though the focus of the present study was to prioritize the adoption factors, there emerged certain barriers that hinder SMEs from adapting ICT. There are a number of studies which have attempted to identify these barriers. A few other barriers of ICT adoption as identified by some studies include the lack of:

- Required knowledge about the innumerable benefits [20].

- Confidence, persisting doubts regarding its dependability, paucity of budgetary allocation, etc. [19].

- Understanding about the host of online security issues and threats.

- Familiarity about the technologies with respect to ICT [2].

Other issues include cost related factors associated with hardware, software, training, paucity of suitable technology and easily accessible e-business platforms, business related barriers and attitudinal barriers etc.

\section{Conclusion}

The study was undertaken to investigate the potential ICT adoption dynamics of SMEs. AHP, which is a multi-criteria decision-making approach, was used in the study. A case-based approach was adopted to prioritise the dynamics, which a firm considers while adopting ICT tools. The paper provides a framework on how a firm needs to approach the ICT adoption while satisfying other requirements. The framework used for the study consisted of several stages. At stage one a pool of criterion was generated by extensive review of literature. The stage two focussed on breaking the criterion into alternatives. At the later stages the analysis was done by assigning the weights and peerto-peer comparison. Priorities were determined by combining the criteria and alternatives under the stated goal. Sensitivity analysis was carried out to identify the robustness of results by making changes into the weights of criterion.

The findings of the study indicate that SMEs adopt ICT to have a relative advantage over competitors. This was followed by affordability and ease of use and value creation and productivity, while compatibility is one of the least concerned aspects. Moreover, the "individual characteristics of entrepreneurs" are the highly influential criteria for ICT adoption among SMEs. Among the individual characteristics, the technological self-efficacy and the personal characteristics of entrepreneurs are the forces that influence SMEs to go for ICT adoption. On the other hand, when economic aspects are considered, profitability emerged as the number one priority of SMEs for ICT adoption. However, in the organizational aspects, the top management support is considered as the number one factor for SMEs for ICT adoption. Though the study focused on the adoption dynamics, certain barriers were also taken into consideration. Future research can be done in order to focus on the barriers of ICT adoption faced by SMEs. The framework proposed in the study could be utilised to enlist the highly delicate barriers. We earnestly hope that this study acts as a trigger for further studies in this area. 


\section{References}

[1]. World-Bank (2020). Small and Medium Enterprises (SMEs) Finance- Improving SMEs access to finance and finding innovative solution to unlock sources of capital. Retrieved from:

https://www.worldbank.org/en/topic/smefinance. [accessed: 10 January 2020].

[2]. García Manjón, J. V., Mompó, R., \& Redoli, J. (2016). Accelerating innovation in small and mediumsized enterprises in the ICT services sector. SAGE Open, 6(3). DOI: 10.1177/2158244016670198

[3]. M. Naushad (2019). Arrays of Intellectual Capital among SMEs in Saudi Arabia. J. Adv. Res. Dyn. Control Syst. 11, 2175-2180.

[4]. Sulphey, M. M., \& Alkahtani, N. (2017). Economic security and sustainability through social entrepreneurship: the current Saudi scenario. Journal of security and sustainability issues, 6(3).

[5]. Duan, X., Deng, H. and Corbitt, B. (2012), "Evaluating the critical determinants for adopting emarket in Australian small-and-medium sized enterprises", Management Research Review, 35(3/4), 289-308. https://doi.org/10.1108/01409171211210172

[6]. Eze, S. C., Awa, H. O., Okoye, J. C., Emecheta, B. C., \& Anazodo, R. O. (2013). Determinant factors of information communication technology (ICT) adoption by government-owned universities in Nigeria. Journal of Enterprise Information Management, 26(4), 427-443.

[7]. Kilangi, A. M. (2012). The determinants of ICT adoption and usage among SMEs: The case of the tourism sector in Tanzania (Dissertation). Netherlands. Vrije Universiteit.

[8]. Rogers, Everett M. , Linda Williams, and Rhonda B. West 1977 Bibliography of the diffusion of innovations. Stanford University, Stanford, CA: Institute for Communications Research.

[9]. Rogers, E. M. (2010). Diffusion of innovations. Simon and Schuster.

[10]. Jeyaraj, A., Rottman, J. W., \& Lacity, M. C. (2006). A review of the predictors, linkages, and biases in IT innovation adoption research. Journal of information technology, 21(1), 1-23.

[11]. Selamat, Z., Jaffar, N., \& Kadir, H. A. (2011, August). ICT adoption in Malaysian SMEs. In Proc. of International Conference on Management and Service Science (Vol. 8, pp. 135-139).

[12]. Ismail, R., Jeffery, R., \& Van Belle, J. P. (2011). Using ICT as a value adding tool in South African SMEs. Journal of African Research in Business \& Technology, 2011, 1-12.

[13]. Awa, H. O., \& Ojiabo, O. U. (2016). A model of adoption determinants of ERP within TOE framework. Information Technology \& People, 29(4), 901-930.

[14]. Khalifa, A. B. (2016). Determinants of information and communication technologies adoption by Tunisian firms. Journal of Innovation Economics Management, (2), 151-177.
[15]. Kossaï, M., de Souza, M. L. L., Zaied, Y. B., \& Nguyen, P. (2019). Determinants of the Adoption of Information and Communication Technologies (ICTs): the Case of Tunisian Electrical and Electronics Sector. Journal of the Knowledge Economy, 1-20.

[16]. Damanpour, F., \& Schneider, M. (2006). Phases of the adoption of innovation in organizations: effects of environment, organization and top managers 1. British journal of Management, 17(3), 215-236.

[17]. Ramdani, B., Chevers, D., \& Williams, D. A. (2013). SMEs' adoption of enterprise applications: A technology-organisation-environment model. Journal of Small Business and Enterprise Development, 20(4), 735-753.

[18]. Kabanda, S., \& Brown, I. (2017). A structuration analysis of Small and Medium Enterprise (SME) adoption of E-Commerce: The case of Tanzania. Telematics and Informatics, 34(4), 118132.

[19]. Ongori, H., \& Migiro, S. O. (2010). Information and communication technologies adoption in SMEs: literature review. Journal of Chinese Entrepreneurship, 2(1), 93-104.

[20]. Naushad, M. (2018). A study on the antecedents of entrepreneurial intentions among Saudi students. Entrepreneurship and Sustainability Issues, 5(3), 600-617.

[21]. Ghobakhloo, M., Arias-Aranda, D., \& BenitezAmado, J. (2011). Adoption of e-commerce applications in SMEs. Industrial Management \& Data Systems, 111(8), 1238-1269.

[22]. Tarute, A., \& Gatautis, R. (2014). ICT impact on SMEs performance. Procedia-social and behavioral Sciences, 110, 1218-1225.

[23]. Dedrick, J., Gurbaxani, V., \& Kraemer, K. L. (2003). Information technology and economic performance: A critical review of the empirical evidence. $A C M$ Computing Surveys (CSUR), 35(1), 1-28.

[24]. Olise, M. C., Anigbogu, T. U., Edoko, T. D., \& Okoli, M. I. (2014). Determinants of ICT adoption for improved SME's performance in Anambra State, Nigeria. American International Journal of Contemporary Research, 4(7), 163-176.

[25]. Alam, S. S., \& Noor, M. K. M. (2009). ICT adoption in small and medium enterprises: An empirical evidence of service sectors in Malaysia. International Journal of Business and management, 4(2), 112-125.

[26]. Dwivedi, Y. K., Papazafeiropoulo, A., Ramdani, B., Kawalek, P., \& Lorenzo, O. (2009). Predicting SMEs' adoption of enterprise systems. Journal of enterprise information management, 22(1/2), 10-24.

[27]. Saaty, T. L. (1977). A scaling method for priorities in hierarchical structures. Journal of mathematical psychology, 15(3), 234-281.

[28]. Saaty, T. L. (1990). How to make a decision: the analytic hierarchy process. European journal of operational research, 48(1), 9-26.

[29]. Asif, M. (2015). Determining improvement needs in higher education benchmarking. Benchmarking: An International Journal, 22(1), 56-74. 